\title{
EMILIO ADOLFO WESTPHALEN, UN SURREALISTA A MEDIAS
}

doi.org/10.15452/SR.2021.21.0010 ORCID ID: 0000-0002-6911-3439

\author{
Linda Urbancová \\ Universidad Carolina de Praga \\ República Checa \\ lin.urbancova@gmail.com
}

Resumen. El propósito del presente artículo es determinar la similitud entre la poesía surrealista y la de un poeta peruano llamado Emilio Adolfo Westphalen. La primera parte del trabajo se centra en rasgos básicos de la literatura vanguardista de Perú en el período 1920-1930, así como en el procedimiento de la implantación del surrealismo procedente de Europa, el cual fue complejo ya que tuvo que enfrentarse con la situación política del país y con el arduo y parcial rechazo de los movimientos artísticos previos (modernismo, simbolismo, romanticismo). Además, también se enfrentó con la crítica literaria que aún no estaba preparada para la llegada de algo nuevo. En consecuencia, Emilio Adolfo Westphalen expresó su descontento sobre esta fosilizada crítica literaria a sus amigos poetas en su correspondencia y ensayos. Cabe destacar que a Westphalen no sólo le interesaba el surrealismo de otros autores, sino que también le interesó para su poesía. Para poder determinar la similitud entre la poesía surrealista y la de Westphalen se han investigado los ensayos de este autor, la teoría surrealista contenida en los Manifiestos del surrealismo, así como los trabajos críticos de Mirko Lauer y Américo Ferrari, entre otros.

Palabras clave. Emilio Adolfo Westphalen. Perú. Surrealismo. Poesía.

Abstract. Emilio Adolfo Westphalen, a Semi-Surrealist. This work aims to establish similarities between surrealist poetry and the poetry of the Peruvian poet Emilio Adolfo Westphalen. The first part of the text is aiming to outline main characteristics of avant-garde literature in Peru between the years 1920 and 1930 and the process of implantation of a surrealist movement born in Europe. The mentioned process of implantation was hard and complex, especially, because it clashed with the local political system and partial renunciation of the previous movements such as Modernism, Symbolism, and Romanticism. Also, French surrealism 
had to face literary Peruvian critics who were not ready for the arrival of something new. Consequently, Emilio Adolfo Westphalen expressed his discontent over the fossilized literary critic and his poet friends in his correspondence and essays. Westphalen was not only interested in the surrealism of others, but he was also interested in surrealism for his poetry. Our study is based particularly on the following sources: the essays of Emilio Adolfo Westphalen, the surrealist theory included in the Manifestoes of Surrealism, and the critical works by Mirko Lauer, Américo Ferrari, etc.

Keywords. Emilio Adolfo Westphalen. Peru. Surrealism. Poetry. 


\section{Introducción}

Emilio Adolfo Westphalen (1911-2001) fue poeta, crítico literario y un incansable luchador por la cultura peruana. Cabe destacar que fue una persona muy discreta, a la cual le gustaba más trabajar detrás del telón que delante de él. De hecho, su poesía es conocida sólo por unos pocos. Fue a partir de los años noventa cuando comienzan a publicarse artículos dedicados a las diferentes interpretaciones de la poesía westphaleana que, por un lado, trataban de rescatar la minoritaria crítica literaria aparecida en los años cuarenta y cincuenta y, por otro lado, añadían nuevas aportaciones. Los poemarios más estudiados han sido Las ínsulas extrañas (1933) y Abolición de la muerte (1935), los cuales, frecuentemente, han presentado dificultad para clasificarse dentro del canon de los movimientos literarios. De manera similar, Octavio Paz, refiriéndose a Westphalen y su poesía, comenta: «Emilio Adolfo Westphalen es uno de los poetas más puramente poetas entre los que escriben en español. Su poesía no está contaminada de ideología ni de moral ni de teología. Poesía de poeta y no de profesor ni de predicador ni de inquisidor. Poesía que no juzga, sino que se asombra y nos asombra» (Paz, 1979: 163).

El dualismo de ideologías como el cosmopolitismo y el nacionalismo, o el vanguardismo y el indigenismo, dominaban el ambiente literario peruano entre los años 1920 y 1930 . Emilio Adolfo Westphalen, como descendiente de padres alemanes, se inclinaba en sus primeras lecturas y experiencias culturales más hacia Europa que a su propio país natal. Esta determinación le influyó artísticamente pero también intervino en su vida personal donde, como menciona el propio autor, le quitó oportunidades tanto artísticas como laborales. Recordando sus inclinaciones artísticas, Westphalen dice: «[...] aquejado -aun desde antes de salir del país- de esa no sé si virtud o enfermedad que en su jerga literaria denominó J. C. M. «cosmopolitismo» y que yo interpreto como el reconocimiento de aperturas y posibilidades -de la libertad de discrepancia [...]» (Westphalen, 1997: 164). A pesar de lo mencionado, las influencias europeas están en la poesía westphaleana tan esparcidas y solapadas que son apenas reconocibles, lo que resulta en muchas interpretaciones diferentes. En relación a esta problemática, en este artículo trataremos de aproximarnos a una de las preguntas más discutidas por la crítica literaria: la influencia que ha tenido el surrealismo en la poesía westphaleana.

\section{Westphalen y su aproximación al surrealismo como crítico}

Dejando un poco atrás el complejo contexto histórico-social de Lima, entre los años 1920 y 1930 podemos observar una paulatina llegada de diferentes movimientos artísticos tales como el futurismo, dadaismo, expresionismo o surrealismo al campo literario limeño. Con el desarrollo y la teoría de la vanguardia peruana destacó el escritor José Carlos Mariátegui y su revista cultural Amauta (denominada originalmente Vanguardia), donde aparecieron las primeras menciones sobre el surrealismo en Perú. No obstante, la implantación y aceptación del surrealismo en este país como un nuevo movimiento literario fue muy parecida al resto de los movimientos vanguardistas. No sólo las nuevas inspiraciones llegadas de Europa tenían que enfrentarse en el territorio peruano con la política nacional agitada por el creciente poder de los bandos izquierdistas, sino que también lo hacían con la crítica literaria que aún no estaba preparada 
para la llegada de algo nuevo. Por esta razón, estos movimientos literarios procedentes de Europa jamás fueron considerados como un centro de atención. De este modo, durante esa década no llegaron a desarrollar su verdadero potencial ni dejaron huellas significativas en el ambiente literario peruano. Además, cabe destacar que el público apenas conocía las obras vanguardistas que, según la opinión del crítico Mirko Lauer, eran pocas. Asimismo, en Perú nunca surgieron manifiestos literarios (Lauer, 2000).

En este ambiente es donde se formó Emilio Adolfo Westphalen, un poeta que nunca quiso formar parte de ningún movimiento literario y que, desde una temprana edad y gracias a la fuerte influencia de su amigo Xavier Abril, reconoció el carácter propio del campo literario peruano y sus críticos, los cuales formaban los temas principales en la correspondencia de estos dos autores (Lefort, 2007).

El descontento sobre la fosilizada crítica literaria que no quería dejar entrar a lo que venía de Europa lo expresó Westphalen no sólo en su correspondencia, sino también en sus ensayos. Además, este autor acusó a los críticos literarios por no entender a los movimientos vanguardistas, entre los cuales también estaba el surrealismo. En un ensayo así criticaba a los escritores Luis Alberto Sánchez y Estuardo Núñez, los cuales habían coincidido en sus trabajos con el uso desmedido e inexacto del término «surrealismo»:

En realidad, uno no llega a adquirir un concepto claro de lo que quieren significar con él. En L. A. Sánchez, su uso es obsesivo, le aplica siempre que no encuentra otro sustantivo o adjetivo: habla de los cocktails surrealistas de Martín Adán, de la mezcla de indigenismo y surrealismo que se da en Oquendo, de un efímero pontífice surrealista (Xavier Abril), Vallejo se anticipa al surrealismo, Enrique Peña inicia el surrealismo, el surrealismo literario de AMAUTA. Después de esta enumeración, no nos extraña al no encontrar un solo poema surrealista en su Antología, y al reconocer que si esos poetas se denominan surrealistas, no conocen del surrrealismo más que el nombre que emplean como vocablo exótico para deslumbrar a los amigos (Westphalen, 1997: 33).

Respecto al crítico Estuardo Núñez, apunta que sus referencias al surrealismo:

Tampoco son más acertadas; porque si en un momento menciona el Segundo Manifiesto del Surrealismo, estamos seguros que no lo hubiera hecho en ese tono si hubiera leído algunas páginas del libro. Algunas gentes todavía no quieren enterarse que el surrealismo no es una escuela literaria más, ni una nueva perceptiva, sino nada menos que una nueva actitud humana (Westphalen, 1997: 33).

En el ensayo sobre estos dos críticos literarios y su relación con el surrealismo, Westphalen concluye: «¿Sería demasiado pedir a los críticos de poesía en el Perú que antes de emplear los términos tuvieran la preocupación de enterarse de las cosas que ellos nombran?» (Westphalen, 1997: 34).

La crítica de Westphalen en los años treinta no se limitaba sólo a los críticos literarios limeños sino también a sus amigos poetas cuya obra y estilo de poesía consideraba transicional. Así, Westphalen consideraba carente de experiencia emocional profunda y, por consiguiente, artificial, a la poesía de los autores que trataban de copiar la imaginería vanguardista de Europa 
centrada en el materialismo de la edad moderna. Este autor, siempre crítico también de su propia creación poética, describió en una carta escrita en junio del año 1931 a su amigo Xavier Abril su nueva visión para su poesía: «[...] en lo futuro he de procurar que mi poesía no se ciña sino a su libertad y espontaneidad, a lo más oculto e insobornable de mi psiquis, sin las preocupaciones cerebrales y constructivistas que malogran gran parte de mi obra pasada [...]» (Lefort, 2007). Esta cita del año 1931 es probablemente la primera indicación que a Westphalen no sólo le interesaba el surrealismo de otros, sino que también le interesaba para su propia poesía.

\section{Surrealismo y Westphalen, el autor}

Generalmente, los críticos literarios difieren en sus opiniones en cuanto a la pregunta de si Westphalen fue o no surrealista. Así, en diferentes estudios, lo podemos encontrar descrito como surrealista, surrealista heterodoxo, surrealista no ortodoxo, autor que se acerca al surrealismo o autor con una poética incalificable.

Aunque el propio autor siempre negaba su adherencia al movimiento artístico fundado por André Breton, en sus ensayos siempre plasmaba más elogios que críticas al mismo. A diferencia de Xavier Abril, el cual estaba fascinado por el psicoanálisis y el marxismo (Fernández-Cozman, 2006: 48), para Westphalen el surrealismo significaba una visión que ponía en el centro de atención a la poesía. Lo consideró como una desesperada tentativa por convertir la poesía en sistema de vida. Además, como otros surrealistas, destacaba la importancia de la poesía como un instrumento del conocimiento que era capaz de revelarnos y alumbrar nuevos rincones de la realidad y de nosotros mismos. Según Víctor Vich: «Los surrealistas sostenían que la condición del sujeto es la de haber quedado reprimido (a efectos de la racionalidad y de los hábitos culturales), por lo que era preciso romper tales barreras para hacer emerger una realidad inédita y desconocida» (Vich, 2020: 99). Cabe repetir que Westphalen también quería para su poesía una libertad total sin restricciones cerebrales que resultó en una «formación de las relaciones entre „yo“y „otro“, „yo“y „mundo“» (Bary, 1988: 104).

De igual forma vieron los surrealistas a la poesía como una herramienta del cambio que, además, supuestamente enriquecía la vida y conducía hacia su plenitud. El propio Westphalen (1997: 88) asumió en sus ensayos una postura similar cuando dijo que «su identificación del espíritu de la creación poética con el factor de rebeldía y cambio que movía al hombre, trasformando a la sociedad y con ésta a las condiciones generales de la existencia, seguramente causaría extrañeza entre quienes aún consideraban a la poesía como un género literario delimitado por las reglas de versificación». Y añadió que «el hombre debía tener bastante fuerza para mirarse frente a frente en este espejo hechizado que era la poesía. Allí podía ver lo que era y lo que podría ser porque la poesía no era solamente conocimiento del hombre y toma de posesión del mundo, sino que también era el acicate de todo cambio, el fermento de la imaginación» (Westphalen, 1997: 88).

Respecto a determinadas obras surrealistas, Westphalen admitió que leyó algunos textos de Breton, entre ellos el Segundo manifiesto del surrealismo, por el cual se sintió influido (Cárdenas y Elmore, 2011: 20), por tanto no es de extrañar que la lectura de la definición westphaleana 
de la misión del poeta se acerque a la definición surrealista de proceso creativo y a la búsqueda de otra realidad tumbada en el espíritu humano (Breton, 2005: 91). Así, Westphalen apunta:

Entre la poesía y su creador será posible establecer siempre relaciones múltiples de distinta índole, de alcances varios, pero siempre tenemos el impulso primero, la necesidad interior que agita extrañamente al espíritu y le hace traducir en imágenes que opone a la realidad, su disconformidad, su ansia de un mundo erigido según otros postulados. Aunque acaso, como en todo intento de querer presionar en definiciones limitadas y profanas lo en sí mismo complejo y rico como poesía misma, la oposición que presentamos entre poeta y realidad no se ajustan exactamente a una fiel descripción del suceso. Como el poeta mismo es parte de la realidad, la oposición no será absoluta sino relativa a aspectos que anhela desterrar, que quiere hacer retornar a la escena de la cual nunca debieron haber emergido; para señalar otros que son de su gracia, aunque no los pueda sino barruntar, sino percibir como espejismo de dicha o gloria (Westphalen, 1997: 87).

Los surrealistas se servían del automatismo psíquico, el cual se convirtió en una fuente confiable y libre para descubrir lo que se hallaba obstaculizado por la cultura y sociedad. Según los surrealistas, un acto poético era, por naturaleza, involuntario, y se producía siempre como negación del sujeto.

El objeto se volatilizaba y el sujeto desaparecía también. Así se suprimía el duelo entre sujeto y objeto, y el poeta se transformaba en poema, que era esencialmente un lugar de encuentro de dos realidades donde no había yo, no había creador, sino una suerte de fuerza poética que soplaba donde quería y producía imágenes gratuitas e inexplicables. La misión del poeta consistía en atraer esa fuerza poética y convertirse en un cable de alta tensión que permitiera la descarga de imágenes (Paz, 1972: 148-149).

De Westphalen ya hemos oído algo parecido. Así, este autor dice: «Esta especie de comunión universal, de inmersión poética en que se anulan objeto y sujeto es para muchos de nosotros todavía una cima inaccesible aunque intuida, ensoñada o, simplemente, deseada» (Westphalen, 1997: 422). Según Westphalen, el primer impulso interno llega al autor de repente sin previsión y para atraer este primer impulso:

[...] sería recomendable -ya en pleno proceso de creación- que el presunto autor se pusiera en perfecto estado de disponibilidad - se abriera a las más profundas sugerencias interiores y lograra situarse -sin casi darse cuenta- en esa encrucijada anímica en que convergen la mayor cantidad posible de evocaciones comprobaciones presentimientos y fulguraciones y en donde -entre lo aprendido y lo inventado- se puede recurrir a todas las capas o estratos de conciencia e inconsciencia. [...] Todo esto es más fácil de lo que algunos temen o imaginan porque la voluntad no tiene mucha parte en el asunto, ya que escribir un poema es casi como tener un sueño igualmente imprevisible e incontrolable (Westphalen, 1997: 148).

Además, de modo parecido a los surrealistas, Westphalen presentaba la actividad poética como una labor de intermediario ya que, según él, más recibe el autor de lo que da. Así, podemos adivinar de la cita expresada en el párrafo anterior que Westphalen admitía que la voluntad no 
tenía gran importancia en el proceso de la creación poética, pero tenía alguna. Se estaba acercando al concepto de escritura automática, e indirectamente mostraba dudas sobre su forma ortodoxa sugerida por otros autores surrealistas. No olvidemos que el Primer manifiesto surrealista define la poesía surrealista por su automatismo, así que Westphalen no podría ser llamado en sentido estricto un surrealista. Además, estamos de acuerdo con lo que apunta Ferrari (2003) cuando dice que los versos westphaleanos están casi siempre cargados de sentido y de la técnica del verso que los surrealistas no apoyaban. Asimismo, coincidimos con lo que escribió Castillo (1979) cuando dijo que la poesía de Westphalen comunicaba sensaciones y conceptos, aspecto que no tenía sentido para la escritura automática.

Según Westphalen, el poema surge del más amplio margen de nuestras posibilidades de emoción y de sensibilidad. Por otro lado, la convicción bretoniana afirma que un poema puede ser formado por la mezcla no ordenada de trozos de palabras recortadas de un periódico. No obstante, ¿no era también el mismo Breton en su Segundo manifiesto del surrealismo quien condenó al fracaso a los poemas surrealistas que no se basaban en alguna emoción?

Como hemos visto hasta ahora, la teoría del surrealismo pronunciada por Breton en sus manifiestos, sin duda fue capital para Westphalen, sosteniendo su formación. No obstante, hay que añadir que ciertas opiniones o actitudes del movimiento crearon en nuestro autor determinados anticuerpos. Así, Westphalen con frecuencia acentuaba en sus ensayos que la violencia en toda forma le parecía despreciable.

Alejándonos un poco de la teoría, cabe mencionar que Westphalen, junto a su amigo César Moro, organizaron en Perú en el año 1935 la Primera exposición surrealista, para la cual compuso un par de poemas los cuales debían, según él, servir como aproximaciones a la poesía surrealista. Sin embargo, el propio autor en sus ensayos recuerda que pese a que en el evento se mostraban cuadros surrealistas y a que el folleto de la exposición incluía dichos poemas, la gente no entendió el surrealismo y, por consiguiente, lo consideró una cursilería. De nuevo queda otra vez comprobada la indisponibilidad del ambiente cultural peruano de los años treinta para la llegada de nuevas influencias europeas. Westphalen nunca quiso que estos poemas se publicaran en ningún libro o antología. Además, cuando en algún artículo periodístico de la época lo mencionaban como surrealista, el autor solía escribir a la dirección de los periódicos o revistas solicitando que eliminaran el apodo surrealista, puesto que al único que se le podía considerar como surrealista peruano era, según la opinión de Westphalen, César Moro.

\section{Conclusiones}

Con todo lo expuesto anteriormente, podemos concluir que el surrealismo figuró en la década 1920-1930 en Perú y su ambiente literario como un reflejo pasajero, cuyas bases esenciales fueron acogidas por muy pocos. Sin embargo, el encuentro de Westphalen con el surrealismo pintado por Breton en sus manifiestos fue crucial, porque le brindó una comodidad para crear de manera más libre y sin limitaciones. En consecuencia, Westphalen llegó a ser un crítico del surrealismo, además de ser su defensor y propagador.

En concreto hay que destacar la similitud entre las definiciones surrealistas de otra dimensión regida y construida por la poesía y la teoría poética westphaleana cuyo centro siempre 
formaba un mundo erigido según otros postulados. También los surrealistas como Westphalen consideraban al poeta como un intermediario en el proceso de la creación poética. Por otro lado, el propio autor no quiso pertenecer al movimiento bretoniano y su teoría sobre el acto poético partía de una profunda experiencia emocional que oscilaba entre lo inventado y lo aprendido, que se oponía a la definición surrealista del automatismo psíquico y la escritura automática, por los cuales estaba definido el surrealismo en el Primer manifiesto. Igualmente, en sus ensayos cuestionaba directamente esta manera de creación literaria. Por las razones expuestas en este artículo, la poesía westphaleana tuvo en común con la poesía surrealista la teoría, más que la práctica. Westphalen aceptó la actitud vital surrealista pero no sus técnicas de escritura o su retórica. Es por ello que considero a Westphalen un surrealista, pero solo a medias y, además, solo a veces.

\title{
Bibliografía
}

У BARY, Leslie (1988). «El surrealismo en Hispanoamérica y el „yo“ de Westphalen». Revista de Crítica Literaria Latinoamericana 14.27, pp. 97-110. https://doi.org/10.2307/4530367 [19-5-2020].

$\checkmark \quad$ BRETON, André (2005). Manifesty surrealismu. Praha: Hermann \& Synové.

ע CASTILLO, Luis Alberto (1979). «E.A.W. de Las ínsulas extrañas a Abolición de la muerte o inegación de la negación?». La sagrada familia 4, pp. 32-35.

У CÁRdenas, Federico; ELmore, Peter (2011). «En la pared del tiempo». Libros $\&$ Artes, 48-49, pp. 18-20.

\ FERNÁNDEZ-COZMAN, Camilo (2006). «César Moro y los ecos del surrealismo francés en el Perú». Boletín de la Academia Peruana de la Lengua 42. https://doi.org/10.46744/bapl.200602.004 [22-6-2020].

$\checkmark$ FERRARI, Américo (2003). La soledad sonora: voces poéticas del Perú e hispanoamérica. Lima: PUCP.

У LAUER, Mirko (2000). «Poesía vanguardista peruana, 1916-1930». Hueso húmero 37, pp. 3-30.

$\checkmark$ LEFORT, Daniel (2007). «Emilio Adolfo Westphalen en la Lima de los años treinta: once cartas a Xavier Abril» Quehacer 166. http://www.desco.org.pe/recursos/sites/indice/749/2088.pdf [12-3-2020].

У PAZ, Octavio (1972). El arco y lira. México, D. F.: Fondo de Cultura Económica.

У PAZ, Octavio (1979). In/mediaciones. Barcelona: Barral Editores.

$\checkmark$ VICH, Víctor (2020). Poetas peruanos del siglo XX: Lecturas críticas. Lima: Fondo <Editorial de la PUCP.

$\checkmark$ WESTPHALEN, Emilio Adolfo (1997). Escritos varios: sobre arte y poesía. Lima: Fondo de Cultura Económica.

\author{
Linda Urbancová \\ Filozofická fakulta Univerzity Karlovy \\ nám. J. Palacha $1 / 2$ \\ 11638 PRAHA \\ República Checa
}

